\title{
Evaluation of Percutaneous Pedicle Screw Fixation in Patients with Pyogenic Spondylitis of the Thoracolumbar Spine
}

\author{
Katsunori Fukutake*, Akihito Wada, Daisuke Kamakura, Kazumasa Nakamura, Shintaro Tsuge, \\ Keiji Hasegawa, Hiroshi Takahashi
}

Department of Orthopedic Surgery, Toho University Omori Medical Center, Tokyo, Japan

Email: *katsunori.fukutake@med.toho-u.ac.jp, nyagira@med.toho-u.ac.jp, daisuke.kamakura@med.toho-u.ac.jp, kazumasa.nakamura@med.toho-u.ac.jp, shintarou.tsuge@med.toho-u.ac.jp, keiji.hasegawa@med.toho-u.ac.jp, drkan@med.toho-u.ac.jp

How to cite this paper: Fukutake, K., Wada, A., Kamakura, D., Nakamura, K., Tsuge, S., Hasegawa, K. and Takahashi, H. (2020) Evaluation of Percutaneous Pedicle Screw Fixation in Patients with Pyogenic Spondylitis of the Thoracolumbar Spine. Open Journal of Orthopedics, 10, 303-312. https://doi.org/10.4236/ojo.2020.1011031

Received: October 18, 2020

Accepted: November 20, 2020

Published: November 23, 2020

Copyright () 2020 by author(s) and Scientific Research Publishing Inc. This work is licensed under the Creative Commons Attribution International License (CC BY 4.0).

http://creativecommons.org/licenses/by/4.0/ (c) (i) Open Access

\begin{abstract}
Background: Basic principle for the treatment of pyogenic spondylitis (PS) is conservative care, but surgical intervention is often required when conservative treatment may fail. We have experienced many conservative cases of various complications due to long-term bed rest and poor pain control. Recently we have adopted percutaneous pedicle screw (PPS) fixation for the treatment of PS as a minimally invasive spine stabilization (MISt) fusion to reduce such morbidity of the conservative care. Objective: To evaluate the impact of PPS fixation in patients with PS. Study Design: A retrospective analysis of the medical records. Subjects, Methods: We reviewed 54 consecutive patients who underwent treatment in our hospital for PS during 2005-2018 and observed for more than 12 months. Of those we excluded cases showing effectiveness to initial treatment (it was defined fever relief or C-reactive protein (CRP) inversion in 3 weeks of antibiotics) so that this study is a retrospective study in cases showing initial treatment resistance. Finally, this study included 29 cases. Medical records of these 29 cases were reviewed for baseline, organism isolated and its detection rate, the clinical outcome in 12 months (Discharge, Transfer, Death), the period from the first visit to our hospital to fever relief, CRP inversion, ambulation, and Discharge or Transfer. Results: These cases were divided into two groups, the conservative group (C-group): 17 cases, and the PPS group (P-group): 12 cases. There is no statistically significant difference in fever relief $(\mathrm{p}=0.051)$ and CRP inversion $(\mathrm{p}=0.208)$. The period to ambulation and discharge or transfer was significantly shorter in group $\mathrm{P}(\mathrm{p}=0.020, \mathrm{p}=0.031)$. 1-Year survival rate was $92 \%$ in the $\mathrm{P}$-group, and $71 \%$ in the $\mathrm{C}$-group. There is no statistically significant difference $(p=0.354)$ between the two groups. The rate of Discharge
\end{abstract}


to home and care facility is $58 \%$ in $\mathrm{P}$-group, and $47 \%$ in C-group. And the rate of Transfer is $34 \%$ in P-group, and 35\% in C-group. Conclusion: PPS fixation was effective to achieve shortening the period to ambulation and discharge or transfer. But it was not effective in infection control. This suggests that PPS fixation should be aggressively administered to patients who can expect pain relief and early ambulation by PPS fixation in the patient of PS showing resistance to initial treatment.

\section{Keywords}

Pyogenic Spondylitis, Percutaneous Pedicle Screw Fixation

\section{Introduction}

Pyogenic spondylitis (PS) is relatively rare; however recent observations suggest that incidence of PS is increasing [1]. And it is related to the improved life expectancy of patients with chronic diseases, especially in the elderly [2] [3]. The incidence of PS has been estimated at 2.4 cases per 100,000 populations [1] with the incidence increasing with aging, 0.3 per 100,000 among persons younger than 20 years of age to 6.5 per 100,000 among persons older than 70 years of age [4] [5].

Basic principle for the treatment of PS is conservative care, but various complications have been observed in many conservative cases due to long-term bed rest, poor pain control, and exacerbation of infection. Thus, treatment methods have been gradually reformed and surgical intervention has been often required when conservative treatment may fail. Recent study indicates that percutaneous pedicle screw (PPS) fixation is a feasible and effective technique to achieve immediate pain release, and reduce morbidity due to long-term bed rest, poor pain control [6]. In our hospital, around 2010, there was a turning point in the treatment methods for PS. We adopted PPS fixation as a minimally invasive spine stabilization (MISt) for patients who were resistant to initial treatment.

In this study, a comparative study was conducted between the conservative group and the PPS group in cases showing initial treatment resistance, to evaluate the impact of PPS fixation in patients with PS resisted to initial treatment.

\section{Material and Methods}

\subsection{Subject}

We retrospectively reviewed 54 consecutive patients who underwent treatment in our hospital for PS during 2005-2018 and followed up for at least 12 months. Of those we excluded cases showed effectiveness to initial treatment (it was defined fever relief and C-reactive protein (CRP) inversion in 3 weeks of intravenous antibiotic) so that this study is a retrospective study in cases showing initial treatment resistance. Finally, this study included 29 cases. 
To evaluate the impact of PPS fixation, these cases were divided into two groups, the conservative group: 17 cases, and the PPS group: 12 cases. Since 2010, PPS fixation has been relatively selected, but cases with poor general condition have selected conservative treatment. The protocol of the present study was approved by the Ethics Committee of the Toho University Omori Medical Center (\#M20012).

\subsection{Extraction of Clinical Information}

Medical records of these 29 cases were reviewed for demographics including age and gender, medical history and related diseases, organism isolated and it's detection rate, the clinical outcome in 12 months (Discharge, Transfer, death), the period from the first visit to our hospital to fever relief, CRP inversion, ambulation, and Discharge or Transfer. We defined CRP inversion as a CRP level decrease to $<0.3 \mathrm{mg} / \mathrm{dl}$.

The diagnosis of PS was based on clinical presentations, blood test (CRP, and white blood cell count), radiological findings on X-rays and magnetic resonance imaging (MRI). Especially, MRI findings are important, PS presents a signal decrease in T1-weighted sequences and a signal increase in T2-weighted sequences in the anterolateral vertebral body near endplate at the early stage.

\subsection{Statistical Analysis}

The statistical analysis was performed using JMP ${ }^{\circledast} 14$ (SAS Institute Inc., Cary, NC, USA). Age, BMI, and the period from the first visit to our hospital to fever relief, CRP inversion, ambulation, and Discharge or Transfer were analyzed using Mann-Whitney U tests. And the gender, rate of compromised host, organism detection rate, and 1-year survival rate were analyzed using the Fisher's exact test.

\section{Results}

\subsection{Baseline}

29 patients were included in this study, 23 patients (79\%) were male and 6 patients (21\%) were female, and aged 48 - 90 years old (median70.2 \pm 10.9 SD). A list of all cases is shown in Table 1 . These cases were divided into two groups, the conservative group (C-group): 17 cases, and the PPS group (P-group): 12 cases.

All patients' characteristics are summarized in Table 2. There was no statistically significant difference in age, gender, rate of compromised host. BMI in the P-group was higher than the C-group ( $\mathrm{p}=0.036) .16$ cases had associated disease with compromised hosts, diabetes in 6 cases, malignant tumor in 6 cases, skin disease in 3 cases, hemodialysis in 3 cases (there is some overlapping.).

Treatments are summarized in Table 3 . In the C-group, 8 cases underwent Percutaneous nucleotomy $(\mathrm{PN})$. In the P-group, lesion dissection and bone transplantation were added in 3 cases. 
Table 1. A list of all cases.

\begin{tabular}{|c|c|c|c|c|c|c|c|c|c|c|c|c|c|c|c|c|c|}
\hline Case & y.o. & $\operatorname{sex}$ & $\begin{array}{l}\text { hight } \\
(\mathrm{cm})\end{array}$ & $\begin{array}{l}\text { Weight } \\
(\mathrm{kg})\end{array}$ & $\begin{array}{c}\text { BMI } \\
\left(\mathrm{kg} / \mathrm{m}^{2}\right)\end{array}$ & $\begin{array}{c}\text { Compromized } \\
\text { host }\end{array}$ & $\begin{array}{c}\text { Affected } \\
\text { Level of } \\
\text { Vertebra }\end{array}$ & $\begin{array}{l}\text { Blood } \\
\text { culture }\end{array}$ & $\begin{array}{l}\text { PN } \\
\text { culture }\end{array}$ & $\begin{array}{l}\text { Causative } \\
\text { organisms }\end{array}$ & Operation & $\begin{array}{l}\text { Period } \\
\text { to fever } \\
\text { relief } \\
\text { (days) }\end{array}$ & $\begin{array}{l}\text { Period to } \\
\text { ambulation } \\
\text { (days) }\end{array}$ & $\begin{array}{c}\text { Period } \\
\text { to CRP } \\
\text { inversion } \\
\text { (days) }\end{array}$ & $\begin{array}{c}\text { Period to } \\
\text { discharge } \\
\text { or transfer } \\
\text { (days) }\end{array}$ & Outcome & $\begin{array}{c}\text { 1-year } \\
\text { survival }\end{array}$ \\
\hline 1 & 69 & $\mathrm{~F}$ & 144.8 & 41.1 & 19.6 & $(+)$ & T9-L1 & $(+)$ & $(-)$ & MRSA & - & 32 & 80 & 41 & 161 & Discharge & $(+)$ \\
\hline 2 & 70 & M & 175 & 70 & 22.9 & $(+)$ & $\mathrm{L} 4 / 5$ & $(-)$ & $(+)$ & $\alpha$ Streptococcus & - & 23 & 29 & 76 & 83 & Discharge & $(+)$ \\
\hline 4 & 73 & M & 165.6 & 64 & 23.3 & $(+)$ & $\mathrm{L} 1 / 2$ & $(-)$ & $(+)$ & $\alpha$ Streptococcus & - & 59 & 69 & 69 & 113 & Discharge & $(+)$ \\
\hline 5 & 70 & M & 161.8 & 56.1 & 21.4 & $(-)$ & $\mathrm{L} 4 / 5$ & $(+)$ & $(-)$ & MSSA & - & 26 & 73 & 66 & 105 & Discharge & $(+)$ \\
\hline 6 & 70 & M & 162 & 61.7 & 23.5 & $(-)$ & L2-4 & $(+)$ & $(+)$ & Enterococcus & - & 42 & 67 & 58 & 122 & Transfer & $(+)$ \\
\hline 8 & 78 & $\mathrm{~F}$ & 160 & 39.5 & 15.4 & $(+)$ & $\mathrm{L} 3 / 4$ & $(+)$ & $(+)$ & MRCNS & - & - & - & - & 180 & $\begin{array}{c}\text { Death } \\
\text { discharge }\end{array}$ & $(-)$ \\
\hline 9 & 88 & F & 150 & 46 & 20.4 & $(-)$ & $\mathrm{L} 4 / 5$ & $(+)$ & & MSSA & - & 98 & 98 & 97 & 98 & Transfer & $(+)$ \\
\hline 10 & 52 & M & 169 & 95.2 & 33.3 & $(-)$ & $\mathrm{L} 4 / 5$ & $(+)$ & $(+)$ & MRSA & - & 83 & 125 & 94 & 153 & Transfer & $(+)$ \\
\hline 11 & 56 & M & 175 & 77.5 & 25.3 & $(-)$ & L5/S & $(-)$ & & unknown & - & 25 & 27 & 34 & 45 & Discharge & $(+)$ \\
\hline 12 & 67 & M & 160 & 46 & 18.0 & $(+)$ & $\mathrm{T} 6 / 7$ & $(+)$ & & MSSA & $\mathrm{PPS}+\mathrm{BT}$ & 16 & 32 & 30 & 68 & Transfer & $(+)$ \\
\hline 13 & 56 & M & 171 & 53.2 & 18.2 & $(-)$ & T4-7 L5/S & $(+)$ & & MSSA & - & 44 & 76 & 83 & 76 & Transfer & $(+)$ \\
\hline 14 & 88 & M & 158 & 55.5 & 22.2 & $(+)$ & $\mathrm{L} 4 / 5$ & $(-)$ & $(-)$ & unknown & - & 32 & 60 & 89 & 124 & Discharge & $(+)$ \\
\hline 16 & 80 & M & 163.4 & 71 & 26.6 & $(+)$ & T8-10 & $(+)$ & & $\begin{array}{c}\text { Pseudomonas } \\
\text { aeruginosa }\end{array}$ & $\mathrm{PPS}+\mathrm{BT}$ & 77 & 57 & 92 & 132 & Discharge & $(+)$ \\
\hline 17 & 69 & M & 165 & 65.4 & 24.0 & $(-)$ & T1/T2 L5/S & $(+)$ & $(+)$ & MRSA & PPS & 15 & 46 & 54 & 190 & Transfer & $(+)$ \\
\hline 18 & 90 & M & 162.5 & 52.8 & 20.0 & $(+)$ & $\mathrm{L} 3 / 4$ & $(+)$ & & E.coli & - & 33 & 35 & 52 & 156 & Transfer & $(-)$ \\
\hline 19 & 83 & M & 159 & 60.3 & 23.9 & $(-)$ & T9-11 & $(+)$ & & E.coli & PPS & 11 & 37 & 47 & 61 & Discharge & $(+)$ \\
\hline 20 & 78 & F & 164 & 62.4 & 23.2 & $(-)$ & $\mathrm{L} 1 / 2 \mathrm{~L} 5 / \mathrm{S}$ & $(+)$ & & E.coli & PPS & 33 & 83 & 72 & 84 & Discharge & $(+)$ \\
\hline 21 & 74 & F & 135 & 43 & 23.6 & $(+)$ & L3-S & $(-)$ & & unknown & PPS & 16 & 18 & 130 & 57 & Transfer & $(+)$ \\
\hline 22 & 60 & M & 161.2 & 60.9 & 23.4 & $(+)$ & T8/9 & $(+)$ & & MRSA & - & 96 & 72 & 96 & 96 & Discharge & $(-)$ \\
\hline 23 & 66 & M & 164 & 77.5 & 28.8 & $(+)$ & $\mathrm{L} 3 / 4$ & $(+)$ & $(+)$ & $\begin{array}{l}\text { Streptococcus } \\
\text { pneumoniae }\end{array}$ & $\mathrm{PPS}+\mathrm{BT}$ & 32 & 31 & 45 & 49 & Discharge & $(+)$ \\
\hline 24 & 73 & M & 180 & 98 & 30.2 & $(+)$ & $\mathrm{T} 7 / 8$ & $(+)$ & & $\begin{array}{l}\text { peptoniphilus } \\
\text { asaccharolyticus }\end{array}$ & PPS & 44 & 41 & 98 & 98 & Discharge & $(+)$ \\
\hline 25 & 58 & M & 169 & 67 & 23.5 & $(-)$ & L4-S & $(+)$ & & CNS & - & - & - & - & 140 & $\begin{array}{c}\text { Death } \\
\text { discharge }\end{array}$ & $(-)$ \\
\hline 26 & 71 & $\mathrm{~F}$ & 153 & 43.7 & 18.7 & $(-)$ & $\mathrm{L} 5 / \mathrm{S}$ & $(+)$ & $(-)$ & $\begin{array}{c}\text { Group B } \\
\text { Streptococcus }\end{array}$ & - & 37 & 41 & 103 & 128 & Discharge & $(+)$ \\
\hline 27 & 69 & M & 162 & 70 & 26.7 & $(-)$ & $\mathrm{L} 4 / 5$ & $(+)$ & & MSSA & PPS & 28 & 38 & 62 & 77 & Transfer & $(+)$ \\
\hline 28 & 48 & M & 163 & 72 & 27.1 & $(+)$ & L5/S & $(+)$ & & MSSA & PPS & 33 & 34 & 46 & 55 & Discharge & $(+)$ \\
\hline 29 & 58 & M & 158.9 & 72.4 & 28.7 & $(+)$ & $\mathrm{L} 3 / 4$ & $(+)$ & & MSSA & PPS & 32 & 25 & 39 & 71 & Discharge & $(+)$ \\
\hline
\end{tabular}


Table 2. Characteristic.

\begin{tabular}{|c|c|c|c|c|}
\hline & all cases & P-group & C-group & P-value \\
\hline $\mathrm{n}$ (cases) & 29 & 12 & 17 & \\
\hline Age (y.o.) & 70.7 & 69.1 & 71 & 0.616 \\
\hline Male (cases)/female (cases) & $23 / 6$ & $10 / 2$ & $13 / 4$ & 0.653 \\
\hline BMI $\left(\mathrm{kg} / \mathrm{m}^{2}\right)$ & 23 & 25 & 22 & 0.005 \\
\hline Rate of compromized host (\%) & 55 & 58 & 50 & 0.774 \\
\hline \multicolumn{5}{|l|}{ Associated disease } \\
\hline Diabetes (cases) & 6 & 3 & 3 & 0.744 \\
\hline Malignant tumors (cases) & 6 & 3 & 3 & 0.744 \\
\hline Steroid use (cases) & 6 & 1 & 5 & 0.347 \\
\hline Hemodialysis (cases) & 3 & 0 & 3 & 0.444 \\
\hline Organism detection rate (\%) & 89.7 & 91.6 & 88.9 & 1.000 \\
\hline Blood culture positive (cases/cases) & $24 / 29$ & $10 / 12$ & $14 / 17$ & 0.946 \\
\hline $\mathrm{PN}$ positive (cases/cases) & $8 / 10$ & $2 / 2$ & $6 / 8$ & 0.453 \\
\hline \multicolumn{5}{|l|}{ Level affected } \\
\hline Thoracal (cases) & 9 & 6 & 3 & 0.068 \\
\hline Lumber (cases) & 21 & 6 & 15 & 0.025 \\
\hline
\end{tabular}

Table 3. Treatment.

\begin{tabular}{cccc}
\hline & all cases & P-group & C-group \\
\hline PPS & 9 & 9 & 0 \\
PPS + lesion dissection and bone transplantation & 3 & 3 & 0 \\
PN & 10 & 2 & 8 \\
External fixation & 9 & 0 & 9 \\
\hline
\end{tabular}

\subsection{Organism}

The causative organism was identified in 26 cases (89.7\%). There is no statistically significant difference in organism detection rate between the two groups (Table 2). The most common organism was Staphylococcus spp. (15/26 cases), in which methicillin-resistant Staphylococcus aureus (MRSA) was 40\% / 14 cases). In descending order, Escherichia coli was 3 cases, $\alpha$-Streptococcus was 2 cases, the others were 1 case each (Streptococcus pneumoniae, Pseudomonas aeruginosa, Peptoniphilus asaccharolyticus, Enterococcus, Group B Streptococcus, Group G Streptococcus). The breakdown of both groups is shown in Table 4. 
Table 4. Causative organisms.

\begin{tabular}{cccc}
\hline & all cases & P-group & C-group \\
\hline MRSA & 15 & 7 & 8 \\
MRCNS & 5 & 1 & 4 \\
Escherichia coli & 1 & 0 & 1 \\
a-Streptococcus spp. & 3 & 2 & 1 \\
Streptococcus pneumoniae & 2 & 0 & 2 \\
Pseudomonas aeruginosa & 1 & 0 & 1 \\
Peptoniphilus asaccharolyticus & 1 & 1 & 1 \\
Enterococcus spp. & 1 & 0 & 1 \\
Group G Streptococcus & 1 & 0 & 1 \\
Group B Streptococcus & 1 & 0 & 2 \\
Unknown & 1 & 0 & 1 \\
\hline
\end{tabular}

\subsection{The Period of Recovery and the Clinical Outcome}

We investigated the period from the first visit to our hospital to fever relief, CRP inversion, ambulation, and discharge or transfer. There is no statistically significant difference in fever relief $(p=0.051)$ and CRP inversion $(p=0.208)$. The period to ambulation and discharge or transfer was significantly shorter in group $\mathrm{P}$ $(\mathrm{p}=0.020, \mathrm{p}=0.031)$.

The outcomes were determined at 12 months after the start of treatment, discharge, transfer, and death. In the P-group, 1 case died of intestinal obstruction and 1-year survival rate was $92 \%$. In the C-group, 5 cases died of infarction-sepsis ( 3 cases), acute myocardial infarction ( 1 case), and unknown ( 1 case). 1 -year survival rate was $71 \%$. The P-group was relatively high 1 -year survival rate, but there is no statistically significant difference $(p=0.354)$ between the two groups (Table 1). The rate of Discharge to home and care facility is $58 \%$ in P-group, and $47 \%$ in C-group. And the rate of Transfer is 33\% in P-group, and $35 \%$ in C-group. These are shown in Table 5.

\section{Discussion}

In the present study, PS account for $2 \%-4 \%$ of bone and joint infections [7]. There has been a considerable increase in patients of pyogenic spondylitis during the last 15 years [8]. Some reports show this increase was attributed to improved life expectancy of patients with chronic disease [2] [9], better diagnostic imaging [10]. And also reported percentages of elderly patients (over 60 years old) among total cases of pyogenic spondylitis treated surgically are $40 \%-46 \%$ [11] [12] [13]. In this study, the percentage of elderly patients was $75.9 \%$, and it 
Table 5. Period of recovery and clinical outcome.

\begin{tabular}{lcccc}
\hline & All cases & P-group & C-group & P-value \\
\hline Period to & & & & \\
Fever relief (days) & 35.5 & 30.6 & 39.6 & 0.186 \\
CRP inversion (days) & 65.1 & 61.7 & 68.7 & 0.376 \\
Ambulation (days) & 50.9 & 40.2 & 61.6 & 0.04 \\
Discharge or transfer or death discharge (days) & 107.6 & 93.4 & 116.3 & 0.046 \\
Clinical outcome & & & & \\
CRP inversion rate (\%) & 79.4 & 83.4 & 76.5 & 0.659 \\
Discharge rate (\%) & 51.7 & 58.3 & 47 & 0.556 \\
Transfer rate (\%) & 34.5 & 33.3 & 35.2 & 0.914 \\
$\begin{array}{l}\text { 1 year survival rate (\%) } \\
\text { (\%) }\end{array}$ & 79.3 & 91.7 & 70.6 & 0.354 \\
\hline
\end{tabular}

was $83.3 \%$ in the surgically cases only. This study included cases showed initial treatment resistance, so that percentage of elderly patients is high. And of course, the recent aging of the population has an effect.

Organism detection rate of PS was reported $34 \%-75 \%$ in present studies [14] [15] [16]. In this study the causative organism was identified in 26 cases (89.7\%), it is relatively high compared to previous reports [17] [18]. In our hospital, almost all patients had two sets of blood culture tests performed on admission, and the positive rate of blood culture was relatively high at $82.8 \%$ (24/29 cases). Additional disc culture tests were performed except for cases that antibiotics were administered before consultation to our department and cases where causative bacteria were already found by blood culture, and the positive rate was $80.0 \%$ ( $8 / 10$ cases). The cases have negative blood culture test and positive disc culture test are $40 \%$ ( $2 / 5$ cases). It showed the usefulness of the combined use of these culture tests. The types and proportions of the causative organisms were almost the same as those reported so far [2] [10] [19]. Among these causative organisms, MRSA has the risk of Non-inversion of CRP [9] and Life expectancy reduction [20]. In this study, 6 cases infecting MRSA of those 3 cases (50\%) die in 1 year. And there were total of 6 deaths during the observation period, half of these were due to MRSA infected cases. It shows MRSA related to life prognosis. The C-group may have been disadvantaged because the ratio of MRSA in the C-group was higher than the P-group; it was the limitation of this study.

Surgical treatment strategies in the PS aim at the removal of the infected tissue with fixation [21]. Recently, PPS fixation is the major method of minimally invasive spinal internal fixation, and there are many papers supporting the use of PPS [6] [22] [23]. Especially, some reports suggested PPS fixation without touching the infected tissue is effective in the treatment of pyogenic spondylitis. Deininger, M. H. et al., found that internal immobilization and antibiotic thera- 
py without touching the infected tissue was sufficient to completely resolve spondylodiscitis, even in a completely mobilized patient. PPS fixation is a feasible and effective technique to achieve immediate pain release and avoid long-term immobilization [6]. Recently we also adopted PPS fixation as MISt approach for patients of PS who showed resistance to initial treatment, as shown in these reports. Although the number of cases is small, it is the limitation in this study, it was proved that PPS fixation was effective for achieving a shorter period of ambulation and discharge or transfer, but also, it was ineffective for infection control. In the elderly patient with compromised factors, the inflammatory reaction was prolonged, and it was difficult to early discharge despite PPS fixation. The basic principles of treatment for PS are chemotherapy and the removal of infected tissue and spinal stabilization. The treatment strategy with PPS which has excessive expectations for infection control is not recommended. PPS fixation should be aggressively treated to patients who expect pain relief and early ambulation, in patients with PS. PPS fixation is useful instrument, minimum invasive and convenient. But its indications for PS require further consideration.

\section{Conclusion}

In conclusion, present study shows that PPS fixation was effective to achieve shorten the period of ambulation and discharge or transfer. But it was not effective in infection control, such as fever relief and CRP inversion. This result suggests that PPS fixation should be aggressively administered to patients who can expect pain relief and early ambulation by PPS fixation in the patient of PS showing resistance to initial treatment.

\section{Declarations}

The protocol of the present study was approved by the Ethics Committee of the Toho University Omori Medical Center (\#M20012).

\section{Availability of Data and Materials}

The datasets are available from the corresponding author on reasonable request.

\section{Authors' Contributions}

KF wrote the paper including performing the literature review. HT, KF, ST, and $\mathrm{KH}$ were the principal clinicians who performed spinal surgery. KF and KN participated in the systemic examination and follow-up. AW provided guidance for the literature search, the writing of the paper and proofread the paper. All authors have read and approved the manuscript.

\section{Conflicts of Interest}

The authors declare no conflicts of interest regarding the publication of this paper. 


\section{References}

[1] Zimmerli, W. (2010) Clinical Practice. Vertebral Osteomyelitis. The New England Journal of Medicine, 362, 1022-1029. https://doi.org/10.1056/NEJMcp0910753

[2] Yoshimoto, M., Takebayashi, T., Kawaguchi, S., Tsuda, H., Ida, K., Wada, T. and Yamashita, T. (2011) Pyogenic Spondylitis in the Elderly: A Report from Japan with the Most Aging Society. European Spine Journal, 20, 649-654. https://doi.org/10.1007/s00586-010-1659-4

[3] Gasbarrini, A.L., Bertoldi, E., Mazzetti, M., Fini, L., Terzi, S., Gonella, F., Mirabile, L., Barbanti Brodano, G., Furno, A., Gasbarrini, A. and Boriani, S. (2005) Clinical Features, Diagnostic and Therapeutic Approaches to Haematogenous Vertebral Osteomyelitis. European Review for Medical and Pharmacological Sciences, 9, 53-66.

[4] Kehrer, M., Pedersen, C., Jensen, T.G. and Lassen, A.T. (2014) Increasing Incidence of Pyogenic Spondylodiscitis: A 14-Year Population-Based Study. Journal of Infection, 68, 313-320. https://doi.org/10.1016/j.jinf.2013.11.011

[5] Grammatico, L., Baron, S., Rusch, E., Lepage, B., Surer, N., Desenclos, J.C. and Besnier, J.M. (2008) Epidemiology of Vertebral Osteomyelitis (VO) in France: Analysis of Hospital-Discharge Data 2002-2003. Epidemiology \& Infection, 136, 653-660. https://doi.org/10.1017/S0950268807008850

[6] Deininger, M.H., Unfried, M.I., Vougioukas, V.I. and Hubbe, U. (2009) Minimally Invasive Dorsal Percutaneous Spondylodesis for the Treatment of Adult Pyogenic Spondylodiscitis. Acta Neurochirurgica, 151, 1451-1457.

https://doi.org/10.1007/s00701-009-0377-3

[7] Antunes, J.L. (1992) Infections of the Spine. Acta Neurochirurgica, 116, 179-186. https://doi.org/10.1007/BF01540874

[8] Turunc, T., Demiroglu, Y.Z., Uncu, H., Colakoglu, S. and Arslan, H. (2007) A Comparative Analysis of Tuberculous, Brucellar and Pyogenic Spontaneous Spondylodiscitis Patients. Journal of Infection, 55, 158-163.

https://doi.org/10.1016/j.jinf.2007.04.002

[9] Kugimiya, F., Muraki, S., Nagakura, D., Umekoji, H., Oda, H. and Takahashi, K. (2017) Predictors of Conservative Treatment for Pyogenic Spondylitis. Spine Surgery and Related Research, 1, 135-139.

[10] Carragee, E.J. (1997) The Clinical Use of Magnetic Resonance Imaging in Pyogenic Vertebral Osteomyelitis. Spine, 22, 780-785.

https://doi.org/10.1097/00007632-199704010-00015

[11] Dimar, J.R., Carreon, L.Y., Glassman, S.D., Campbell, M.J., Hartman, M.J. and Johnson, J.R. (2004) Treatment of Pyogenic Vertebral Osteomyelitis with Anterior Debridement and Fusion Followed by Delayed Posterior Spinal Fusion. Spine, 29, 326-332. https://doi.org/10.1097/01.BRS.0000109410.46538.74

[12] Ha, K.Y., Shin, J.H., Kim, K.W. and Na, K.H. (2007) The Fate of Anterior Autogenous Bone Graft after Anterior Radical Surgery with or without Posterior Instrumentation in the Treatment of Pyogenic Lumbar Spondylodiscitis. Spine, 32, 1856-1864. https://doi.org/10.1097/BRS.0b013e318108b804

[13] Pee, Y.H., Park, J.D., Choi, Y.G. and Lee, S.H. (2008) Anterior Debridement and Fusion Followed by Posterior Pedicle Screw Fixation in Pyogenic Spondylodiscitis: Autologous Iliac Bone Strut versus Cage. Journal of Neurosurgery: Spine SPI, 8 , 405-412. https://doi.org/10.3171/SPI/2008/8/5/405

[14] Colmenero, J.D., Jimenez-Mejias, M.E., Sanchez-Lora, F.J., Reguera, J.M., Palomi- 
no-Nicas, J., Martos, F., Garcia de las Heras, J. and Pachon, J. (1997) Pyogenic, Tuberculous, and Brucellar Vertebral Osteomyelitis: A Descriptive and Comparative Study of 219 Cases. Annals of the Rheumatic Diseases, 56, 709-715. https://doi.org/10.1136/ard.56.12.709

[15] McHenry, M.C., Easley, K.A. and Locker, G.A. (2002) Vertebral Osteomyelitis: Long-Term Outcome for 253 Patients from 7 Cleveland-Area Hospitals. Clinical Infectious Diseases, 34, 1342-1350. https://doi.org/10.1086/340102

[16] Hadjipavlou, A.G., Mader, J.T., Necessary, J.T. and Muffoletto, A.J. (2000) Hematogenous Pyogenic Spinal Infections and Their Surgical Management. Spine, 25, 1668-1679. https://doi.org/10.1097/00007632-200007010-00010

[17] Hopkinson, N. and Patel, K. (2016) Clinical Features of Septic Discitis in the UK: A Retrospective Case Ascertainment Study and Review of Management Recommendations. Rheumatology International, 36, 1319-1326.

https://doi.org/10.1007/s00296-016-3532-1

[18] Mylona, E., Samarkos, M., Kakalou, E., Fanourgiakis, P. and Skoutelis, A. (2009) Pyogenic Vertebral Osteomyelitis: A Systematic Review of Clinical Characteristics. Seminars in Arthritis and Rheumatism, 39, 10-17. https://doi.org/10.1016/j.semarthrit.2008.03.002

[19] Matsui, H., Hirano, N. and Sakaguchi, Y. (1998) Vertebral Osteomyelitis: An Analysis of 38 Surgically Treated Cases. European Spine Journal, 7, 50-54. https://doi.org/10.1007/s005860050027

[20] Kokabu, T., Takahata, M., Ishiguro, N. and Iwasaki, N. (2017) Long-Term Prognosis of Hematogenous Vertebral Osteomyelitis: Mortality, Quality of Life, and Pain. Journal of Orthopaedic Science, 22, 822-827. https://doi.org/10.1016/j.jos.2017.05.017

[21] Quinones-Hinojosa, A., Jun, P., Jacobs, R., Rosenberg, W.S. and Weinstein, P.R. (2004) General Principles in the Medical and Surgical Management of Spinal Infections: A Multidisciplinary Approach. Neurosurgical Focus, 17, E1.

[22] Guo, S., Zhu, K., Zhang, S.Y., Ma, B., Yang, M.J., Yan, M.J., Li, X.H., Pan, J., Li, L.J., Wang, Z.G. and Tan, J. (2019) Percutaneous Pedicle Screw Fixation Alone versus Debridement and Fusion Surgery for the Treatment of Early Spinal Tuberculosis: A Retrospective Cohort Study. Medical Science Monitor, 25, 1549-1557. https://doi.org/10.12659/MSM.912538

[23] Kandwal, P., Garg, B., Upendra, B., Chowdhury, B. and Jayaswal, A. (2012) Outcome of Minimally Invasive Surgery in the Management of Tuberculous Spondylitis. Indian Journal of Orthopaedics, 46, 159-164. 